\title{
Otomasi Siaran Radio Menggunakan Open Source Software Rivendell
}

\author{
Robin Maulana ${ }^{1}$ \\ robinmaulana94@gmail.com \\ Universitas Bina Sarana Informatika ${ }^{1}$
}

\begin{abstract}
Media radio broadcast telah berkembang dari propagasi frekuensi radio di udara menjadi penyebaran data digital audio melalui jaringan internet atau yang biasa disebut dengan radio streaming. Radio streaming memudahkan masyarakat agar dapat menikmati beraneka ragam jenis siaran audio yang dapat dijangkau dari berbagai wilayah manapun yang memiliki jaringan internet yang memadai.Selain itu, penggunaan komputer dan internet pada siaran radio streaming memungkinkan adanya otomasi siaran yang tidak tergantung pada keberadaan penyiar secara fisik. Dengan adanya aplikasi otomasi siaran maka menu siaran dapat dipersiapkan jauh hari sebelumnya sesuai jadwal, dan proses siaran dapat terjadi secara autopilot tanpa ada kekhawatiran terjadi kesalahan pemutaran materi siaran. Rivendell adalah salah satu aplikasi berbasis open source (OSS) yang khusus dirancang untuk keperluan ini. Beberapa fitur peting yang sangat bermanfaat pada aplikasi Rivendell untuk proses siaran radio adalah kemampuan untuk memutar berbagai format audio digital, kompatibel dengan berbagai jenis hardware audio, dan tentu saja dukungan komunitas yang luas sebagaimana umumnya aplikasi berbasis open source.
\end{abstract}

Kata kunci: radio broadcast, otomasi siaran, Rivendell

\section{Pendahuluan}

Siaran radio merupakan salah satu aktifitas penyebarluasan informasi suara melalui sarana sarana transmisi di darat, di laut atau di antariksa dengan menggunakan spektrum frekuensi radio atau melalui media lainnya untuk dapat diterima secara serentak dan bersamaan oleh masyarakat dengan perangkat penerima siaran, yang dilakukan secara teratur dan berkesinambungan[1].

Hal utama yang paling penting dari keberadaan siaran radio adalah sajian program atau materi acara yang menarik. Hal ini dapat didukung dengan salah satu komponen acara yang penting yaitu seorang penyiar radio dengan format siaran yang variatif. Siaran Radio yang bagus dan bervariasi tentu dapat menarik perhatian konsumen atau pendengar, sehingga dibutuhkan sistem siaran yang lebih baik.[2].

Dengan demikian manajemen sistem informasi materi siaran yang digunakan harus ditunjang dengan database siaran dan pengaturan durasi iklan yang baik. Sehingga siaran yang sedang berlangsung belum sepenuhnya terkendali dengan baik.

Selain itu untuk lebih efisien dalam penyelenggaraan siaran tersebut, dibutuhkan sebuah sistem yang mampu mengatur secara mandiri (otomasi) materi siaran dan tidak bergantung sepenuhnya pada kru maupun penyiar dalam pengoperasiannya.[3] 
Saat ini banyak tersedia aplikasi komputer berbasis web maupun desktop, baik komersial maupun gratis yang menyediakan diri sebagai perangkat otomasi materi siaran radio.

Rivendell adalah salah satu aplikasi otomasi siaran radio berbasis open source (oss) yang sudah cukup lama dibuat dan memiliki fitur yang cukup lengkap[4]

\section{Tentang Rivendell}

Rivendell adalah solusi otomatisasi siaran radio yang lengkap, dengan fasilitas untuk akuisisi, manajemen, penjadwalan, dan pemutaran konten audio. Ia memiliki semua fitur yang diharapkan dalam sistem otomasi radio modern yang lengkap, termasuk dukungan untuk pengkodean audio PCM dan MPEG, penelusuran suara dan kustomisasi log lengkap serta dukungan untuk berbagai perangkat lunak dan perangkat keras pihak ketiga. Sebagai sistem audio digital yang kuat dan lengkap secara fungsional untuk aplikasi siaran radio, Rivendell menggunakan komponen standar industri seperti Sistem Operasi GNU / Linux, Arsitektur Driver HPI AudioScience dan Mesin Database MySQL. Rivendell tersedia di bawah Lisensi Publik GNU.

\subsection{Fitur Utama}

Berikut beberapa fitur dan keuntungan penggunaan Rivendell sebagai aplikasi otomasi siaran radio :

- Sistem otomasi radio GPL yang lengkap.

- Dirancang untuk penggunaan di udara yang efisien, dengan kontrol besar, ramah layar sentuh.

- Hingga tiga log otomatisasi penuh dapat dioperasikan dari satu komputer.

- Dukungan untuk lingkungan siaran langsung, dengan beberapa array SoundPanel tersedia dengan satu sentuhan jari.

- Semua konfigurasi dilakukan melalui antarmuka sekali klik - tidak diperlukan pengeditan file konfigurasi

- Dukungan untuk format audio PCM16 dan MPEG Layer 2 (dukungan MPEG Layer 2 memerlukan penggunaan kartu suara pilihan yang tersedia dari AudioScience Inc.).

- Dukungan penuh untuk antarmuka audio digital analog dan AES3, menggunakan adaptor audio berkualitas tinggi yang diproduksi oleh AudioScience Inc. dan JACK Audio Connection Kit.

- Didesain oleh penyiar radio, untuk penyiar radio.

- Benar-benar gratis dan terbuka - tanpa dongle, kode buka kunci, kunci perangkat lunak, atau batasan arbitrer lainnya.

\subsection{Spesifikasi Teknis dan Kebutuhan Minimum Sistem}

Rivendell berjalan pada sistem operasi GNU / Linux, dan tersedia di bawah Lisensi Publik GNU. Saat ini mendukung operasi menggunakan ASI Audio Adapters yang tersedia dari AudioScience Inc serta Kit Koneksi Audio Jack.

Untuk dapat menjalankan Rivendell dibutuhkan persyaratan sistem minimum yang disarankan:

- $\quad$ CPU Pentium 4 
- $\quad$ RAM $256 \mathrm{MB}$

- SuSE Linux Professional 9.x

- Kartu Video yang Didukung XFree86

- AudioScience Audio Adapter

- $\quad$ Mouse atau Perangkat Penunjuk lainnya

- Opsional: Monitor Layar Sentuh.

\subsection{Arsitektur Software}

Berikut adalah diagram blok konsep dari aplikasi Rivendell berdasarkan informasi resmi dari sumbernya.

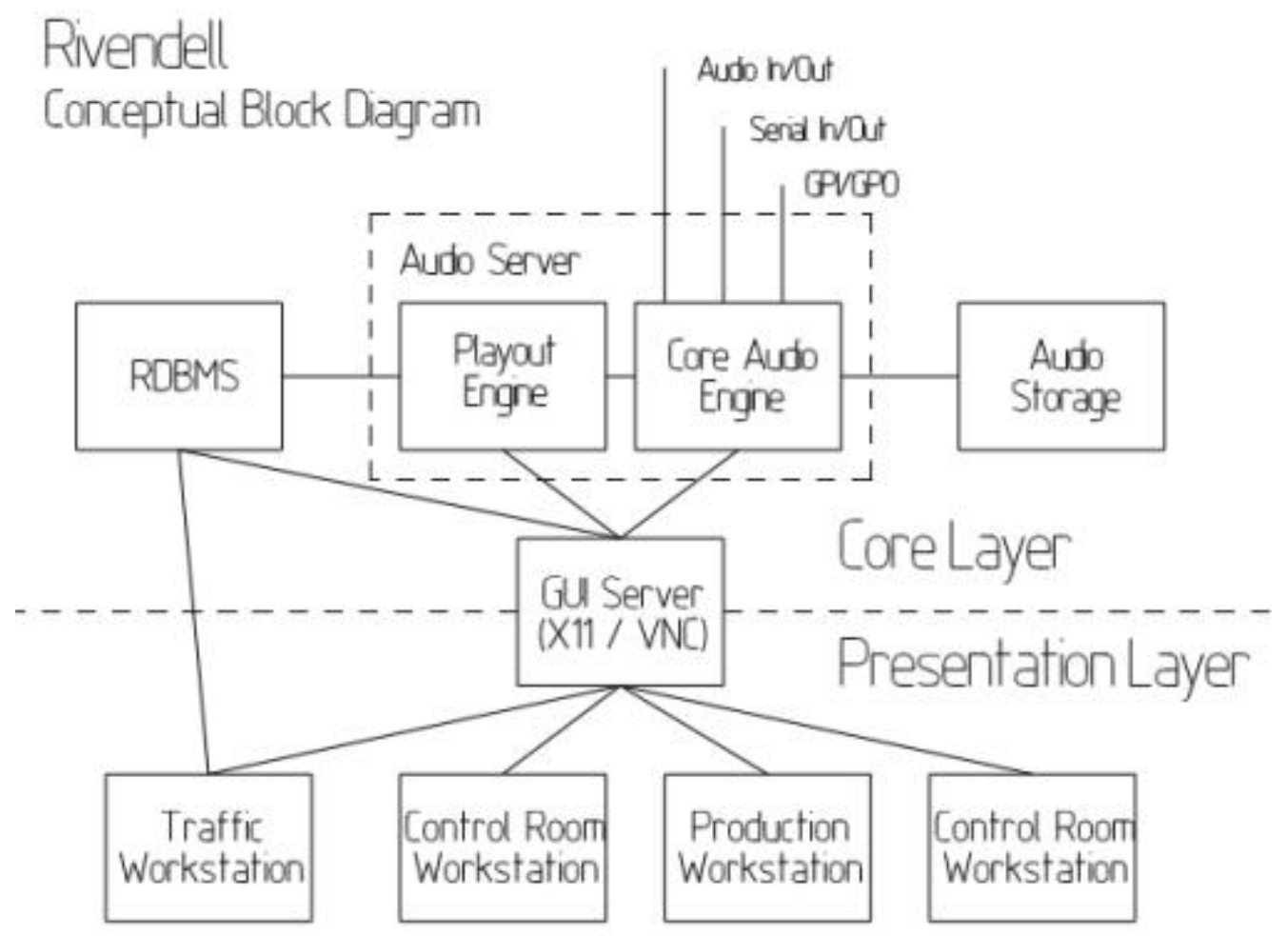

Gambar 1. Blok diagram aplikasi Rivendell (dari www.rivendellaudio.org)

\section{Overview aplikasi}

Pada Rivendell telah terdapat MySQLCC yaitu frontend yang memungkinkan pengguna Rivendell untuk mengelola database. Sebenarnya, Rivendell menginisialisasi satu set dari tabel yang dirancang dengan cara mengelola set data yang diperlukan untuk mengelola Stasiun Radio.

Dalam tabel tersebut pengguna dapat menentukan dan mengelola genre musik, daftar putar, waktu siaran, properti file audio dll. Database diinisialisasi dengan menginstal Rivendell cukup memadai untuk manajemen stasiun radio yang kompleks sehingga pengguna 


\section{Jurnal IImu Komputer}

Februari 2019

tidak perlu memiliki keahlian dalam bidang relasional desain basis data. Namun, keterampilan dan pengetahuan dasar tentang desain basis data relasional akan berguna untuk memodifikasi basis data dengan kebutuhan spesifik pengguna.

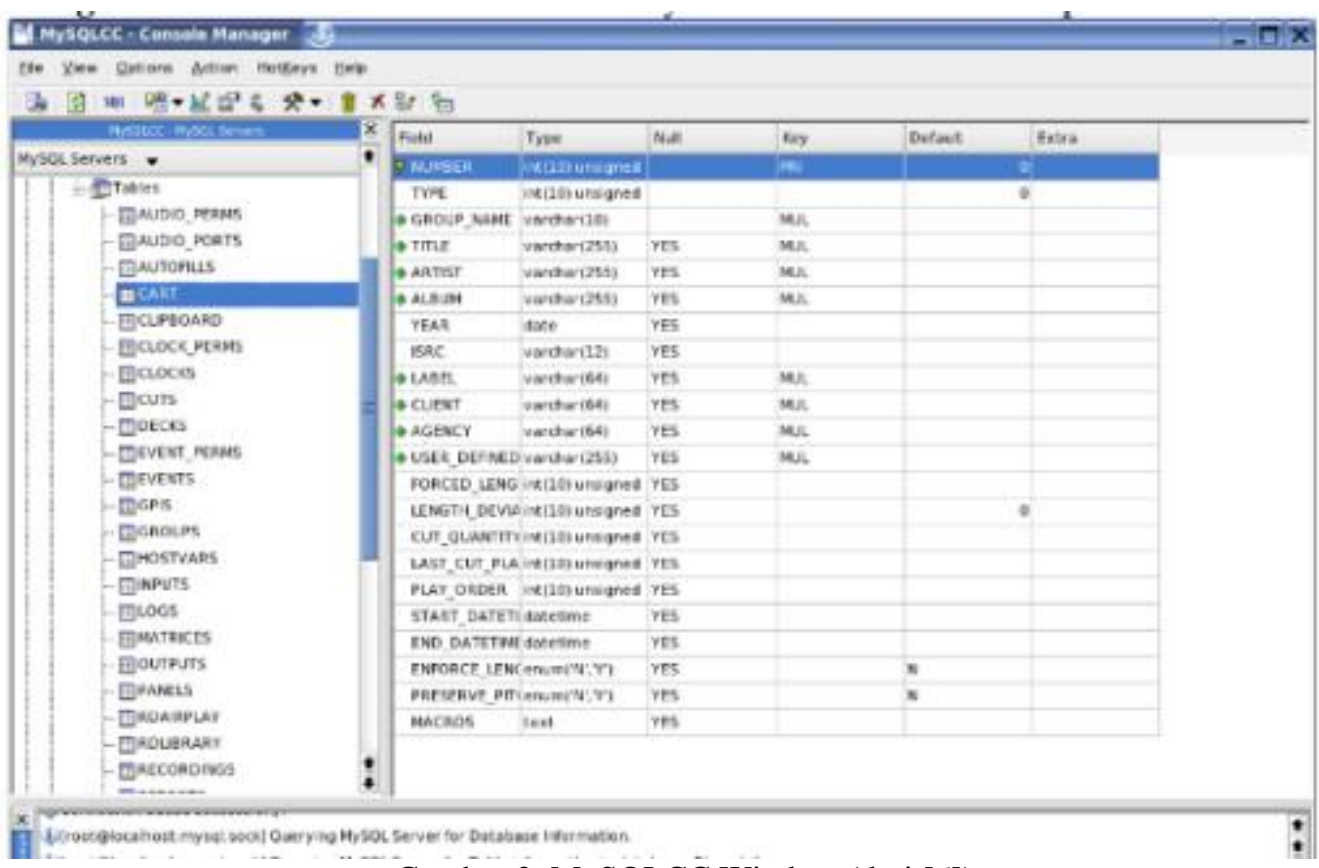

Gambar 2. MySQLCC Window (dari [6])

Seseorang yang bertanggung jawab atas administrasi basis data relasional stasiun radio dapat mengaturnya dengan mudah dengan menggunakan MySQLCC atau RDAdmin. RDAdmin kecil tetapi komponen penting dari Rivendell yang memungkinkan administrator untuk mengelola pengguna, grup, layanan, cadangan, dan pulihkan basis data.

Jadi, jika stasiun radio itu tidak memiliki cukup dana untuk mempekerjakan seorang ahli desain basis data relasional, mungkin dapat melakukan ini sendiri. Aplikasi ini dirancang dengan cara yang memastikan operasi sederhana dan mudah untuk satu stasiun radio atau jaringan radio stasiun. Sebenarnya, pengorganisasian kerja data yang baik membutuhkan pengorganisasian database yang baik dan sebaliknya.

RDAirPlay adalah komponen dari Rivendell yang mengingatkan pada fungsi teknisi radio yang berpengalaman dan ahli audio dari perangkat yang sangat mahal beberapa tahun yang lalu. Saat ini, dimungkinkan untuk melakukan hal yang sama dan bahkan lebih tugas-tugas komplek ini hanya dengan menggunakan komputer pribadi dan perangkat lunak gratis. Tugas bagian ini adalah menyiapkan daftar materi siaran, timing dan interaksi, karena penyiar biasanya harus mengganggu pemutaran agar untuk menyiarkan berita hangat, pengumuman atau melanjutkan program bicara setelah iklan atau musik. 


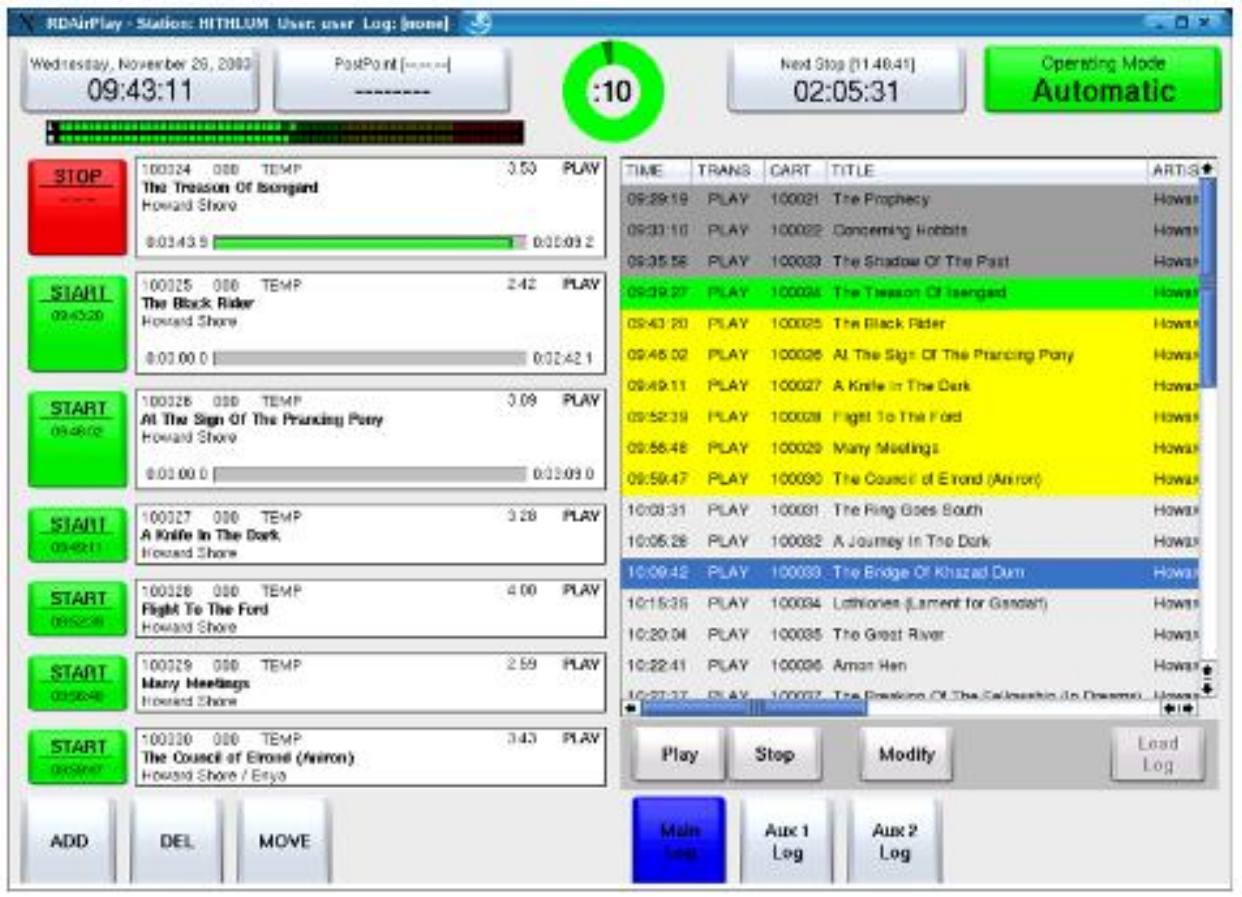

Gambar 3. RDAirplay (dari [6])

Satu karakteristik radio yang sangat penting adalah 'call', yang juga merupakan inti dari misi media independen dan kelompok advokasi. Dengan memberikan kesempatan kepada pendengar untuk mengatakan secara terbuka apa yang mereka pikirkan tentang topik tertentu, untuk berkomunikasi dengan orang lain mengekspresikan pendapat, sikap, keinginan, keluhan, solidaritas atau pesan penting lainnya adalah penting.

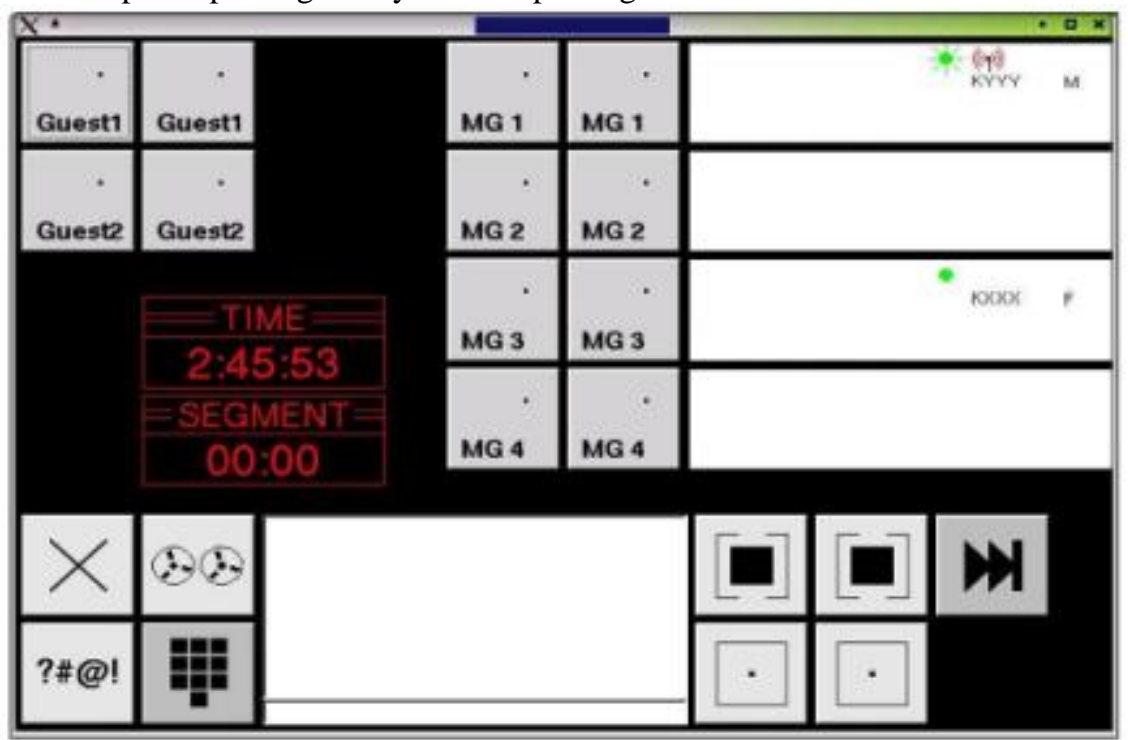

Gambar 4. Call Commander (dari [6]) 
Kebutuhan ini merupakan inti dari stasiun radio yang oleh sebagian orang disebut paradigma "aspirasi masyarakat". Stasiun radio melakukan ini dengan menghubungkan saluran telepon, untuk ini mereka menggunakan perangkat yang dirancang khusus untuk tujuan yang disebut telepon hibrid. Karena saluran telepon memiliki sinyal yang berbeda dari audio normal, tujuan hibrida telepon adalah untuk memungkinkan sinyal saluran telepon didengar di lingkungan audio radio.

Dengan tujuan mengintegrasikan bagian itu dari program radio onair ke aktivitas produksi, pengembang perangkat lunak Rivandell telah mengembangkan perangkat lunak yang disebut Call Commander.

\section{Kesimpulan}

Berdasarkan ulasan diatas dapat simpulan bahwa manajemen sistem informasi siaran radio melalui aplikasi otomasi siaran Ravendell memudahkan pengaturan semua materi siaran karena sudah ditunjang dengan database yang berhubungan dengan penyiaran termasuk pada kegiatan on air yang di mana dapat mengatur dan mengontrol antara acara dan durasi iklan sesuai dengan yang diharapkan. Bila diperlukan fitur tambahan Rivendell, dapat didiskusikan melalui forum komunitas pengembang open source yang sudah mereka sediakan.

\section{References}

[1] Undang-undang Penyiaran no 32 Tahun 2002 tentang Penyiaran

[2] Rismayani dan Hasyrif Sy, Implementasi Manajemen Sistem Informasi Siaran Pada Radio Venus FM Makassar, Konferensi Nasional Sistem \& Informatika 2015

[3] Budi Santoso, Jaringan Dan Otomasi Studio Terintegrasi Stasiun Radio Streaming, Prosiding Seminar Hasil Penelitian DIPA Unitomo, Surabaya, 2017

[4] www.rivendellaudio.org - diakses tgl 10 Januari 2019

[5] Baby Lolita Basyah dkk, Rancang Bangun Aplikasi Radio Online Berbasis Web, Jurnal Ilmiah Fifo, 2015

[6] Vedran Vucic, Free Software Audio Applications for Audio Playback, Recording, Editing, Production and Radio Broadcast Management and Automation, Linux Center Serbia and Montenegro, 2014 